\title{
The new biological revolution: the creation of synthetic human entities with embryo-like features
}

\begin{abstract}
The need to prevent and cure genetic diseases has never been greater in recent times. However, as the quest for heathier offspring and qualitative reproduction grows, buoyed by successes through daunting researches, there are increasingly nascent ramifications of this quest; which is the increasing quest for modern couples to choose babies with some subtle genetic characteristics that goes against the aim of the initial quest to prevent and cure genetic diseases. Modern privileged couples especially in the Western societies are increasing shaping and modelling the type or characteristics of the baby they want to have. This was made possible by the scientific evidence that had emerged. There are increasing concerns that as the society evolves and new research reveals more of human genomics, the ethical boundaries would increasingly become more eroded and less clear cut, and therefore lead to increases in the misuse or abuse of this initial aim of our scientific quest. This could subsequently plunge humanity into self-made destruction. In this article, the author reviews the emerging evidence and speculates the trajectory of the debacle of misuse and abuse of human genomics.

Conclusion: In view of the ethical issues raised in this article, the author wonders what would happen to humanity as its science advances. As humanity exploits its own genomics to its advantage, it could well be exploiting its genomics at its own peril.
\end{abstract}

Volume 8 Issue I - 2019

Anthony Emeka Madu

Specialist Registrar, Obstetrics and Gynaecology

Correspondence: Anthony Emeka Madu, Affiliations: FSRH/ RCOG/BMA/NHS/ILM, UK, Email emymadu@yahoo.co.uk

Received: Januvary 29, 2019 | Published: February 18, 2019

Keywords: biological revolution, synthetic human entities, embryo-like features, genomics, abortion

\section{Introduction}

It is clear that as science advances, new ethical issues arise, and as societal debate evolves, some issues which were initially unacceptable becomes increasingly acceptable. The issue of the recent Irish referendum on 25 May 2018 in which $66.4 \%$ of voters chose to change the abortion law, making abortion up to 12 weeks gestation available on demand, is one instance. This would have been unthinkable in 1983 when there was a similar referendum. The Eight amendments to the Irish constitution was introduced in 1983 and gave equal rights to mother and the unborn baby under the law. It allows abortion when the woman's life is at risk but not in cases of rape, incest or fatal fetal abnormality. As a consequence of this, since 1983 about 170,000 Irish women were reported have travelled to Britain to have abortion. ${ }^{1}$ It is thus clear that societal views on issues evolve with time. At the final count of the recent Irish referendum, after all the results from all the 40 constituencies had been received, the results was as follows;

a) Yes (Drop the Eight Amendment) $66.4 \%$

b) NO (Keep the Eight Amendment) 33.4\%

c) Turnout was $64.1 \%$

The next example is related to the text of this article and is about the issue of in-vitro fertilisation (IVF) when it was in its infancy. At that time, some claimed IVF was too dangerous while others felt it was not natural and moral. The birth of Louise Brown in 1978, in England, appeared to have changed that. Since then about 7 million babies have been born through IVF and the latter is now routine. ${ }^{1}$ However, a tiny minority of the society still debate on the merits of the use of such reproductive techniques.

A similar societal acceptance could also prevail in the future generations of assisted reproduction techniques (ART) advance further. Some argue that if the human race become endangered by, a nuclear disaster, for instance, then, human reproductive potential could be compromised triggering the need to create humans by medical technology. There are those who strongly believe that the ability to create human life from the scratch would be as a result of the effect of some phenomenon rather than our deliberate quests or efforts at ART research. There is clearly a huge biological shift at the centre stage at present and as new biotechnology emerge for treating cancer, fertility, preventing the transmission of serious genetic diseases or saving the lives of very premature babies, there could well be the need for the otherwise unthinkable.

\section{The new advent}

Researchers have recreated the first few days of life in the laboratory thereby shedding more light on the biology of early fetal development, which has not been well understood for some time. This is the stage at which fertility treatments fail and miscarriages are known to occur more commonly.

a) Since 1978, about 1.5\% of babies born in Australia, North America and Western Europe had been through IVF. ${ }^{1}$ This means that the making of human life outside the human body has been routine for over 40 years. However, IVF had the following important issues;

b) Relies on prospective parents having viable sperm and eggs, though Intracytoplasmic Sperm Injection (1CSl) does not necessarily rely on viable sperm cells. ${ }^{3}$

c) There is much to know about why some embryos fail to implant following embryonic transfer (ET) during IVF or implantation following natural conception.

d) Why some embryos die and others continue to grow.

These issues had prompted researchers at Kyoto University in Japan to create sperm and egg cells from different cells of the body. ${ }^{1}$ They took adult skin cells and reprogrammed them into stem cells which has the potential to differentiate to any type of cell. The latter is 
then turned into sperm or egg cell. In 2016, they were able to fertilise some of the eggs they created with sperm cells from normal mice. The embryos created were implanted into a healthy surrogate who subsequently lead to the birth of eight pubs. They repeated same study using created sperm cells and normal mice eggs. Though this study was successful in mice, attempts to do same in humans have only produced rudimentary precursors of the sperm and eggs. In 2017, researchers at the Gurdon Institute of the University of Cambridge, grew primordial germ cells which are precursors of sex cells, for up to the 4week mark. The next move for the researchers was to reach the 8 week mark, a stage these precursors progress to form sperm and egg cells. When these cells are transferred to the human body, they have the potential to mature and restore fertility in couples treated for infertility. However, there are safety issues which would need to be resolved before these are put into clinical use. The scientific community is therefore a long way away from putting this into wider clinical use.

Ethical and other considerations from growing sperm and egg cells from skin cells:

a) People in developed countries could stop having sexual intercourse as a way of having a baby as they can go to a clinic and ask for their skin cells to be made to create gametes (mature haploid germ cell able to unite with the opposite to form a zygote in sexual reproduction). So far the offsprings from these creations are not abnormal, bizarre-looking or prone to genetic diseases, people would not bother.

b) Dozens of sperm and egg cells can be created routinely from skin cell, and there is risk of commercialization.

c) There would not be any need for invasive and painful aspects of IVF; for instance, the expensive egg-harvesting process under ultrasound guidance during the IVF process.

d) The process would be used to eliminate serious genetic diseases that could be transmitted to the offspring.

e) Same sex couples incapable of having their own sperm or egg cells can use this new technology to create sperm and eggs, and thus have genetically related children.

f) Another serious ethical consideration is that couples would use this technology for sex selection and would likely select babies based on nonmedical issues (so called designer babies).

It is important to note that though couples can access information in relation to this, its application seem to be limited. Additionally, our current poor knowledge of how genetic differences sum up to someone's intelligent quotient restricts this practice as well as the fact that per cycle, the harvesting of eggs only yields a dozens of eggs. Further advances in this area came in the use of ovarian stem cell in the research. Researchers at the University of Edinburgh cultured mature human egg cells from a different type of stem cell from human ovary. ${ }^{1}$ This process can help women treated for cancer where treatments for such cancers, for instance involving the use of radiotherapy, chemotherapy, or surgery (bilateral oophorectomy), could lead to loss of fertility. The researchers' idea was that pieces of ovarian tissue could be removed before such treatments and then could be used to create new eggs after the cancer treatment. The eggs created in this way can lead to a new type of IVF treatment in which women undergo just one invasive procedure to retrieve ovarian tissue rather than the current IVF cycles in which women undergo a number of cycles of hormone treatment, and invasive egg harvesting, under ultrasound guidance. Another interesting development to this reproductive biological discourse is that another team of researchers at the University of Cambridge ${ }^{1}$ were reported to have in 2017 coaxed two different mouse stem cells to assemble a biological structure. The latter structure, after only about four days of growth, appeared and behaved like natural embryo. Less than 6 months later, researchers at the Massachusetts Institute of Technology created embryo-like cluster of cells (embryoids) similar to that created by researchers at Cambridge completely from human stem cells. ${ }^{1}$ Researchers at Cambridge and Massachusetts aimed to understand the biology of early stages of human development, which as we know, is difficult to study inside the human body.

These stages include the following;

What occurs following implantation? What happens during subsequent differentiation into layers of cells or tissues? Researchers at Cambridge and Massachusetts were not trying to create viable human embryos from these studies, but such embryoids created from the human stem cells can be used for screening of toxins and pharmacological substances to see if they have potential to cause birth anomalies. Another interesting development was that these embryoids, after about five days of development, appear like the 14day old human embryo. This means that these embryoids, though about five days old, must have skipped earlier stages of development and missed the stage of implantation. Thus the only shot at viability that these embryoids have is outside the uterus. Until recently, there has not been success at external nurturing human embryos up to the stage of implantation which is 3 to 5 days following fertilisation. However, about three years ago, researchers at New York's Rockefeller University nurtured human embryos up to 14 days, well beyond the implantation stage, keeping to the 14days rule. The latter rule is a legal and regulatory requirement adopted by most countries involved in human embryo research.

This 14day rule exists due to the following reasons;

a) It is the time when the primitive streak, a faint band of cells, appears during embryonic development. This is a vital milestone in the development of complex tissue structure of the human embryo.

b) It is a time when the embryo no longer split into identical (uniovular, monozygotic) twin, thus heralding the development of a distinct biological entity.

Timing of division in monozygotic twinning: ${ }^{4}$

a) $<3$ days...dichorionic diamniotic

b) 4 to 7 days....monochorionic diamniotic

c) 8 to 12 days.... monochorionic monamniotic

d) $>12$ days........conjoined twin (very rare)

The zygote enters the uterus in 3 to 5 days after fertilization, and continues to divide to form the blastocyst. Implantation of the latter starts on day 7 and is completed on day $11 .{ }^{5}$ Understandably, there has been curiosity and interest in how to apply the 14day rule to the created embryoids by researchers at Massachusetts Institute of Technology or whether indeed this rule applies to these embryoids to any extent.

In 2017, researchers at Harvard Medical School ${ }^{1}$ aptly called the embryoids "synthetic human entities with embryo-like features" (SHEEFs) and advocated for global debate on the ethical issues raised 
by the creation of these structures. There are already some ethical issues and implications advances at present in relation to creation of these structures;

a) SHEEFs are self-gathering mass of cell and there is no clear cut day to start counting its gestational age and thus the 14day rule does not apply.

b) SHEEFs do not develop in the conventional pathway and may acquire features which are morally troubling, long before the primitive streak appears, at day 14 of embryonic development.

In the near future, more ethical issues or implications could emerge as the wider societal discourse develops and evolves, and as more development in the area pushes the boundaries of how long embryoids, such as SHEEFs, can be grown in the laboratory. As these developments go on, there is yet another serious challenge which is in the area of keeping newborns who arrive very early (less than 24 completed weeks of gestation), that is less than 10 weeks after the 14day rule (emergence of the primitive streak). It is known that neonatologists do not recommend resuscitating newborns who arrived before 22 weeks gestation, as there are clear limitations to the resuscitation technology currently available. In 2017, researchers at the Children's Hospital of Philadelphia, Pensylvania USA, invented the so called "Biobag" which is a fluid filled sac that kept baby lambs alive for four weeks after they were born at equivalent human gestation of 23 to 24 weeks, as judged by lung development. The survival rate at 23 to 24 weeks gestation is less than $50 \%$ currently. Another team at The Extra-Corporal Life Research Laboratory at University of Michigan, USA, also had developed a biosystems which is like "artificial placenta". The "Biobag and "artificial placenta" or other systems can sustain baby lambs until they are ready for artificial ventilation, a precursor to transition to self-sustained breathing, according to Couzin-Frankel J. ${ }^{6}$ The inference that can be drawn from this extra-corporal biosystems are as follows:

a) If the work for human, then the period of commencement of life can be kept going outside the uterus for some time until the neonate could breathe without aids. b) These systems, though aimed at improving the life of babies, could in the future sum up to significant leap into creating human life from the scratch.

\section{Conclusion}

In view of the ethical issues raised in this article, the author wonders what would happen to humanity as its science advances. As humanity exploits its own genomics to its advantage, it could well be exploiting its genomics at its own peril.

\section{Acknowledgments}

None.

\section{Conflicts of interest}

The author declares there are no conflicts of interest.

\section{References}

1. Dolgin E. New beginnings, New scientist. 2018. Pp. 31-33.

2. Emma Graham Harrison. Irish abortion referendum: yes wins with 66.4\% - as it happened. 2018.

3. Madu AE, Odejinmi F, Hussain SY. Negative qualitative BHCG heterotopic pregnancy after intra-cytoplasmic sperm injection. $J$ Obstet Gynaecol. 2004;24(2):196-197.

4. Collins S, Arulkumaran S, Hayes K, et al. Subfertility and reproductive medicine. Third rd ed. UK: Oxford Handbook of Obstetrics and Gynaecology; 2013.18 p.

5. Collins S, Arulkumaran S, Hayes K, et al. Miscellaneous gynaecology. Third rd ed. UK: Oxford Handbook of Obstetrics and Gynaecology; 2013. $74 \mathrm{p}$.

6. Couzin Frankel J. Fluid-filled 'biobag' allows premature lambs to develop outside the womb. 2017. 